\title{
Longitudinal damage of cable-stayed bridges subjected to near-fault ground motion pulses
}

Jiang $Y i^{i^{*}}$ (D) and De'en $Y u^{2}$

\author{
* Correspondence: yijiang@gzhu. \\ edu.cn \\ ${ }^{1}$ College of Civil Engineering, \\ Guangzhou University, Guangzhou, \\ China \\ Full list of author information is \\ available at the end of the article
}

\begin{abstract}
This paper investigated the nonlinear seismic performance of an existing cablestayed bridge longitudinally subjected to a set of simulated near-fault ground motion pulses. An elaborated non-linear finite element model of the bridge was established which particularly considered cable sag effect, material nonlinearity of the tower and the deck. Through non-linear dynamic response analyses, seismic responses of the tower, deck and cables were evaluated at the yield and ultimate state of the structure. In particular, the yield and ultimate state of the structure were defined in the text based on damage levels of the structure and structural integrity requirement. It is revealed that the pulse period $\left(T_{p}\right)$, by determining the relative contribution of multiple modes of the structure, strongly affected the damage process of the structure. As $T_{p}$ was close to the period of first vertical vibration of the deck, the responses of the deck and cables were largely excited so that the deck might yield prior to yield of the tower, the cables failed prior to the ultimate state of the tower, and the deck suffered most of the damage despite of the yielding of the tower.
\end{abstract}

Keywords: Cable-stayed bridge, Seismic damage, Pulse excitation, Damage state

\section{Introduction}

During recent decades, cable-stayed bridges have gained worldwide popularity, owing to aesthetical appearance, structural efficiency and short construction period. This type of structure, characterized by the flexibility of its cable-superstructure system, usually contains a number of long-period modes (usually larger than $1.5 \mathrm{~s}$ ). When cable-stayed bridges are subjected to far-field ground motions, it is consequently advantageous by naturally providing some seismic isolation since characteristic periods of far-field ground motions typically occur at relatively short periods (typically less than $0.5 \mathrm{~s}$ ). In such a situation, cable-stayed bridges are normally able to remain nearly elastic under the design seismic action which satisfies the recommendation of seismic codes like Eurocode 8 (De Normalisation 1998) and Chinese code (MCPRC 2008) and the reinforcement ratio of the tower legs is designed within economical range according to the design purpose. For example, Yokohama Bay Bridge performed as expected

(c) The Author(s). 2021 Open Access This article is licensed under a Creative Commons Attribution 4.0 International License, which permits use, sharing, adaptation, distribution and reproduction in any medium or format, as long as you give appropriate credit to the original author(s) and the source, provide a link to the Creative Commons licence, and indicate if changes were made. The images or other third party material in this article are included in the article's Creative Commons licence, unless indicated otherwise in a credit line to the material. If material is not included in the article's Creative Commons licence and your intended use is not permitted by statutory regulation or exceeds the permitted use, you will need to obtain permission directly from the copyright holder. To view a copy of this licence, visit http://creativecommons.org/licenses/by/4.0/. 
subjected to a ground motion less than the design ground motions during 2011 East Japan Earthquake (Siringoringo et al. 2013).

However, during 1999 Chi-Chi earthquake, the tower of Chi-Lu Bridge suffered severe structural damage including concrete spalling, exposed plastic region and a crack extending upward nearly to the level of the lowest cables (Chang et al. 2004). Chadwell and Fenves (2003) conducted analytical studies to investigate the seismic damage of Chi-Lu Bridge and speculated that ground motion pulses from near-field ground motions at bridge site might lead to the damage of the structure. Quite different from farfield ones, near-field ground motions usually contain long-duration pulses and high peak ground velocities (Jangid and Kelly 2001). It can largely increase the seismic response of cable-stayed bridge since large amplitude spectral accelerations of near-field ground motions occur at long periods where many cable-stayed bridges have significant structural response modes (Wesolowsky and Wilson 2003). To keep the structure elastic under a near-field ground motion, reinforcement ratios of the tower legs need to be greatly increased comparing to its static loading requirement, which was not economical in engineering practices. In fact, some large cable-stayed bridges were designed allowing some structural damage in the towers so as to reduce response uncertainties under unexpectedly large earthquakes, as is the case of Rion-Antirion Bridge in Greece (Combault and Teyssandier 2005) and Stonecutters in China (Kite et al. 2005). It is also accepted in Japanese code (Japan Road Association 2002) that the main tower of cablestayed bridges develops plastic behavior during a design earthquake by carefully investigating and designing its plastic ranges.

Several studies have been conducted to investigate structural damage of cable-stayed bridges during earthquakes. A. Camara (Camara and Astiz 2012) used coupled nonlinear pushover analysis method to estimate the complex inelastic response of cablestayed bridges. The author revealed that the contribution of higher modes of cable stayed bridge (approximately between $1 \mathrm{~Hz}$ and $25 \mathrm{~Hz}$ ) is significant in seismic response and should be included by considering their purely elastic contribution via means of response spectrum analysis. Li et al. (2009) conducted nonlinear time history analysis on a three-tower cable-stayed bridge with rigid system, floating system and passive energy dissipation system which were excited by one far-field ground motion and one nearfield ground motion. The results showed that plastic hinges may form either at the bottom of middle tower or side tower, depending on different systems. Wang et al. (2017) conducted shake table tests on a 1/20-scale cable-stayed bridge model with two $\mathrm{H}$ shaped towers. By exciting the model transversely, damage characteristics of the bridge model were observed including severe damage at upper strut, repairable damage at tower bottom and middle part, and minimal damage at lower strut. Recently, another shake table test was carried out on 1/20 scale model of a single-tower cable-stayed bridge which revealed the vulnerability of the tower, the cable and the bearings of the cable-stayed bridge under near-field ground motions (Yi and Li 2017, 2019).

Despite that above studies shed light on designing the towers of cable-stayed bridges into inelastic stage, no general agreement has been reached on the most vulnerable components of a cable-stayed bridge under a seismic condition. The basic structural form of a cable-stayed bridge consists of towers, the stiffening girder, stay cables, bearings, piers, and foundations. In some studies, the towers suffered from the most significant seismic damage and even failed whereas the nonlinear behavior of other 
components was not considered (Camara and Astiz 2012; Li et al. 2009). Some other studies investigated the elastic-plastic behavior of the deck as well as the effects on the seismic performance of the bridge (Ren and Obata 1999). Meanwhile, the overloading or relaxation of stayed cables was captured in some numerical studies and experimental ones (Wu et al. 2003; Zong et al. 2014). The possible reason for such difference might be that (1) cable-stayed bridges have inherently different coupling effects in the vibrations of various structural components as well as high-order mode effects (Calvi et al. 2010) and (2) the earthquake ground motions, with difference in the spectral contents, would excite the structural components at different amplitudes. There is a clear need to associate the vulnerable components of a cable-stayed bridge with the characteristics of ground motions to have a good understanding of the seismic damage process of this type of bridges.

To this end, this study firstly established an elaborated non-linear finite element model of a real cable-stayed bridge in which several nonlinear responses including cable sag effect, material nonlinearity of the tower and the deck were carefully considered. A set of simulated near-fault pulses were then used to excite the model and the yield and ultimate states of the structure were determined and investigated. In particular, the seismic performance of the tower, the deck and cables at the yield and ultimate state of the structure were evaluated respectively, and the influence of pulse periods on the response of the structure was discussed. Finally, the damage process of the structure affected by pulse periods was analyzed.

\section{Modeling of cable-stayed bridges}

\subsection{Description of bridges}

The cable bridge under study consists of a concrete tower, double-plane cables, a steel deck and two concrete side piers (see Fig. 1). The total length of the bridge is $460 \mathrm{~m}$ divided into two symmetric spans. The inverted Y-shaped single tower is $150 \mathrm{~m}$ high in total and $60 \mathrm{~m}$ wide at the foundation level. The tower is divided into $34 \mathrm{~m}$ bottom tower, $72 \mathrm{~m}$ middle tower, $44 \mathrm{~m}$ anchor zones for cables and a rectangular crossbeam at elevation 34 $\mathrm{m}$. Hollow rectangular boxes are used for the bottom tower and middle tower. The cross section of bottom tower decreases from $14 \mathrm{~m} \times 7.5 \mathrm{~m}$ at the foundation level to $10.8 \mathrm{~m} \times$ $6 \mathrm{~m}$ at crossbeam level with a thickness of $1.3 \mathrm{~m}$ at the long side and $1 \mathrm{~m}$ at the short side while that of the tower middle decreases from $10.8 \mathrm{~m} \times 6 \mathrm{~m}$ to $8.5 \mathrm{~m} \times 5 \mathrm{~m}$ with the thickness of $1.0 \mathrm{~m}$ and $0.8 \mathrm{~m}$ along the long and short side, respectively. The longitudinal steel ratio of tower sections is around $2.17 \% \sim 2.51 \%$ and the axial compression ratio is around $12.1 \% \sim 15.9 \%$ at dead load state. The steel deck is $37.5 \mathrm{~m}$ wide and $3.2 \mathrm{~m}$ high at middle span. It is formed into a streamlined closed box with welded flanges, webs, stiffeners and diaphragms. Table 1 shows the design parameters of the deck. Sixty-eight parallel wire cables, forming at fan types, are used to support the deck. Each of the cables is composed by perfectly arranged $7 \mathrm{~mm}$ high-strength wires with the ultimate stress of $1670 \mathrm{MPa}$. The design parameters of cables are listed in Table 2 . The deck is also supported by two concrete side piers at each span end and the crossbeam of the tower. Two side piers are portal frames which have a height of $34 \mathrm{~m}$ and a width of $25 \mathrm{~m}$. Spherical steel bearings are used for the connection of the deck to side piers and to the tower. Bearings allow for sliding in the longitudinal direction of the bridge but prevent relative transverse and vertical movements of the deck. 


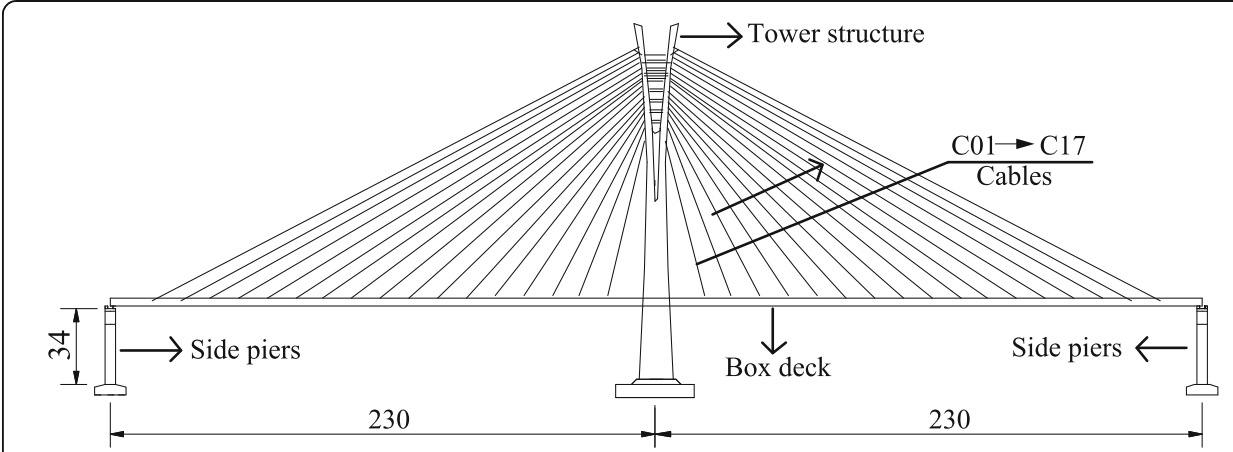

(a) general view of the bridge

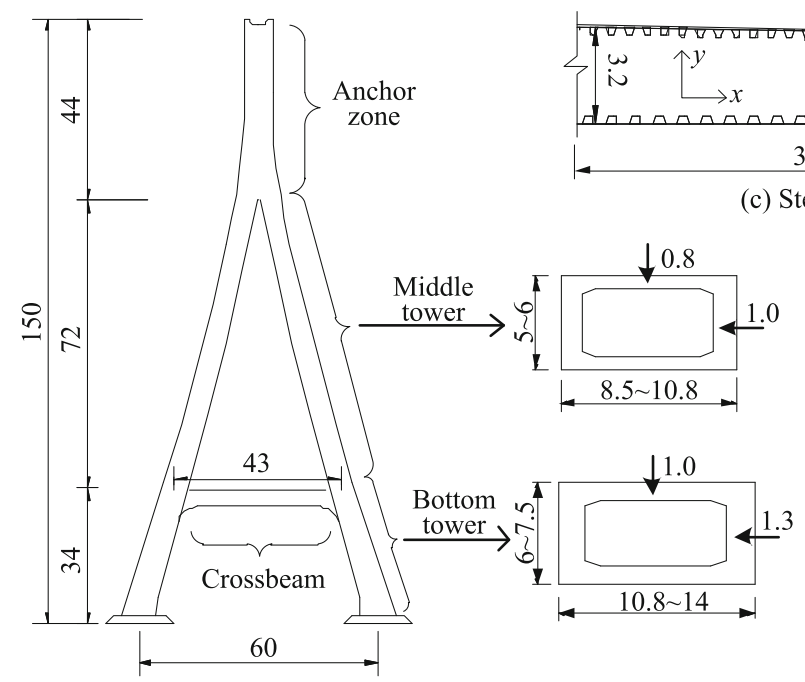

(b) Tower Structure

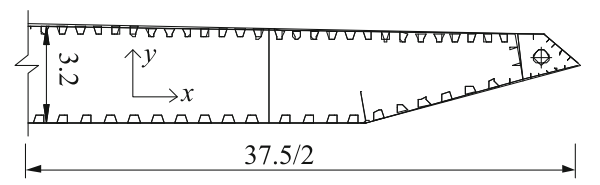

(c) Steel deck

Fig. 1 Schematic of the Cable-stayed Bridge under study

\subsection{Numerical model}

Cable-stayed bridges, with the flexible superstructure system, are characterized by the nonlinear behavior under dynamic loadings. The nonlinear response in this type of structures mainly originates from (i) the cables sag effect; (ii) the action of compressive loads on the deck and the tower; (iii) the effect of large deflections; (iv) material nonlinearity (Ren and Obata 1999; Nazmy and Abdel-Ghaffar 1990). In order to investigate nonlinear dynamic response of the bridge in its longitudinal direction under a series of near-field ground motions, a sophisticated model is established on OpenSees (open system for earthquake engineering simulation) (Mazzoni et al. 2006).

Regarding material nonlinearity and axial force-moment interaction effect, the bottom tower and the middle tower were modeled using nonlinear beam-column elements whose cross section was discretized into unidirectional confined concrete, unconfined concrete and steel fibers (Fiber elements). The strain-stress relationship of the confined and unconfined concrete employed modified Kent-Scott-Park concrete constitution model (Scott et al. 1982) and Karsan-Jirsa loading-unloading law by OpenSees system

Table 1 Design parameters of the deck

\begin{tabular}{lccclll}
\hline $\boldsymbol{A}\left(\mathrm{m}^{\mathbf{2}}\right)$ & $\boldsymbol{I}_{\boldsymbol{x}}\left(\mathrm{m}^{\mathbf{4}}\right)$ & $\boldsymbol{I}_{\boldsymbol{y}}\left(\mathrm{m}^{\mathbf{4}}\right)$ & $J\left(\mathrm{~m}^{\mathbf{4}}\right)$ & $\boldsymbol{E}(\mathrm{MPa})$ & $\boldsymbol{f}_{\boldsymbol{y}}(\mathbf{M P a})$ & $\boldsymbol{M}_{\boldsymbol{y}}(\mathrm{MN} \cdot \mathrm{m})$ \\
\hline 2.19 & 3.56 & 241.6 & 8.63 & $2.05 \times 10^{5}$ & 345 & 689 \\
\hline
\end{tabular}


Table 2 Design parameters of cables

\begin{tabular}{llllllll}
\hline No. & $\boldsymbol{A}\left(\mathbf{m}^{2}\right)$ & $\boldsymbol{F}_{\boldsymbol{o}}(\mathbf{k N})$ & $\boldsymbol{F}_{\boldsymbol{u}}(\mathbf{k N})$ & No. & $\boldsymbol{A}\left(\mathbf{m}^{\mathbf{2}}\right)$ & $\boldsymbol{F}_{\boldsymbol{o}}(\mathbf{k N})$ & $\boldsymbol{F}_{\boldsymbol{u}}(\mathbf{k N})$ \\
\hline C1 & $4.20 \times 10^{-3}$ & 2034.3 & 7014.0 & $\mathrm{C} 10$ & $5.81 \times 10^{-3}$ & 2768.5 & 9702.7 \\
C2 & $3.50 \times 10^{-3}$ & 1724.2 & 5845.0 & $\mathrm{C} 11$ & $5.81 \times 10^{-3}$ & 2934.5 & 9702.7 \\
C3 & $3.50 \times 10^{-3}$ & 1836.8 & 5845.0 & $\mathrm{C} 12$ & $5.81 \times 10^{-3}$ & 3112.9 & 9702.7 \\
C4 & $4.20 \times 10^{-3}$ & 1947.1 & 7014.0 & $\mathrm{C} 13$ & $7.20 \times 10^{-3}$ & 3240.4 & $12,024.0$ \\
C5 & $4.20 \times 10^{-3}$ & 2079.4 & 7014.0 & $\mathrm{C} 14$ & $7.20 \times 10^{-3}$ & 3423.9 & $12,024.0$ \\
C6 & $4.89 \times 10^{-3}$ & 2199.1 & 8166.3 & $\mathrm{C} 15$ & $7.20 \times 10^{-3}$ & 3631.9 & $12,024.0$ \\
C7 & $4.89 \times 10^{-3}$ & 2331.3 & 8166.3 & $\mathrm{C} 16$ & $8.12 \times 10^{-3}$ & 3835.0 & $13,560.4$ \\
C8 & $4.89 \times 10^{-3}$ & 2459.4 & 8166.3 & $\mathrm{C} 17$ & $8.12 \times 10^{-3}$ & 4129.9 & $13,560.4$ \\
C9 & $5.81 \times 10^{-3}$ & 2602.6 & 9702.7 & & & & \\
\hline
\end{tabular}

whereas the tensile strength of the concrete is neglected. The compressive strength of confined and unconfined concrete was calculated $40.8 \mathrm{MPa}$ and $32.4 \mathrm{MPa}$ and the ultimate strains was 0.065 and 0.005, respectively, as shown in Fig. 2a and b. Especially, the ultimate strain of confined concrete was set 0.065 so that $80 \%$ of the compressive strength was retained. The steel fibers were represented using a bilinear strain hardening model. The yield stress was $400 \mathrm{MPa}$ and the ultimate tensile strain was 0.06 (California Department of Transportation 2013) with the kinematic strain hardening ratio of $1.0 \%$, as shown in Fig. 2c.

Based on the material information and section properties provided in Figs. 1 and 2, moment-curvature curves of the tower sections with axial force under dead load state were constructed. As an example, Fig. 3 shows the moment-curvature curve of the tower bottom. The yield point is determined as the outer steel bars reach the yield strain of 0.002 whereas the ultimate point is reached as either the steel bars reach the ultimate tensile stress or the confined concrete reaches the ultimate compressive strain. Therefore, the yield curvature of tower section was calculated $0.000285 \sim 0.000462$ from the tower bottom to the top of middle tower whereas the ultimate curvature was $0.0024 \sim 0.0035$.

Anchored zones of the tower and side piers were represented by linear-elastic element with axial force-moment interaction taken into account. For the anchored zones of the tower, the local damage, namely concrete cracks, large strain of the section or residual deformation, caused stress concentration and slippage of the anchor device for cables. Under such condition, anchorage failure of the cables might occur during the earthquake and the repair is rather difficult after the earthquake. Thus, anchored zones are expected to remain linear during the earthquake and shall be properly designed.

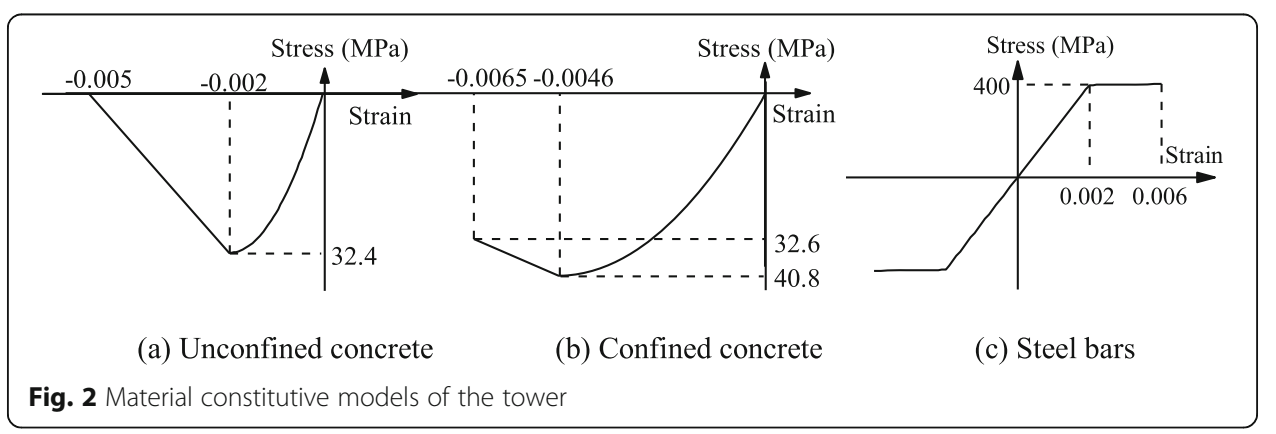




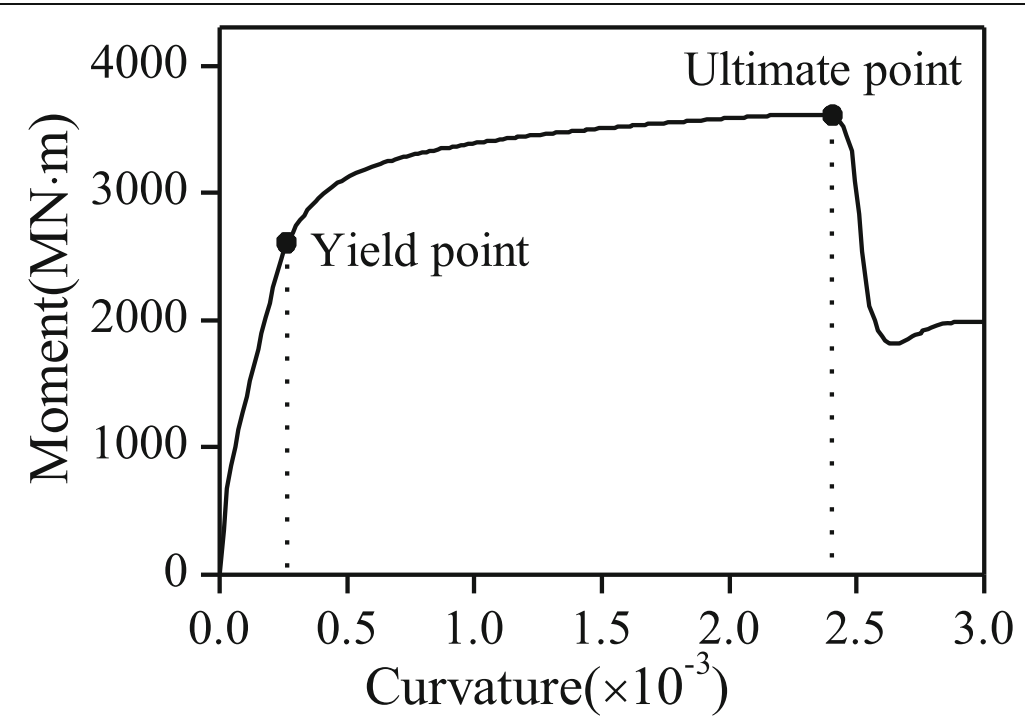

Fig. 3 Moment curvature of the section at tower bottom

And for side piers, longitudinal sliding bearings had so limited influence on the seismic response of the whole bridge that material nonlinearity of side piers was ignored.

Regarding material nonlinearity, the deck was represented by nonlinear beam-column elements. The inelastic behavior was assigned to the weak bending moment-curvature $\left(M_{x}-\phi\right)$ while linear elastic behavior was assigned to all other directions. Using the Ucfiber software (Chadwell and Imbsen and Associates 2002), an original $M_{x}-\phi$ curve was calculated for deck section as shown in Fig. 4 using the stress-stain relationship of steel material showing in Fig. 2c. To apply to the finite element model, an equivalent bilinear curve was established instead of the original curve. The bi-linear curve had the same yield point and ultimate point to the original curve and a strain-hardening ratio of 0.12. For the deck, the axial load-moment interaction was neglected in that the compression stress from the axial load, with a maximum value of $35 \mathrm{MPa}$ under dead load, was quite small comparing to the yield stress of the material (345 MPa).

Cables are modeled using truss element by applying material modulus and the cross section area. Normally, sag effects of cables were approximately taken into account based on constant equivalent elastic modulus from dead loads (Ren and Obata 1999). However, large cable forces were observed for cable-stayed bridges during past

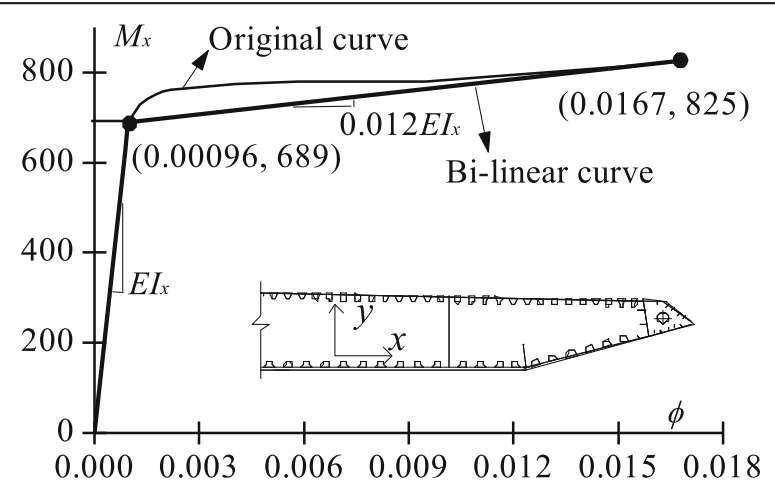

Fig. $4 M_{x}-\varphi$ curve of the deck 
earthquakes with anchorage failure of Ji-Lu Bridge in 1999 Chi-Chi earthquake (Chadwell and Fenves 2003) and possible cable relaxation for Higashi-Kobe Bridge in Hyogoken-Nanbu Earthquake (Ganev et al. 1998). Due to the drape shape, cables experienced "real-time updating" effective stiffness along with varying cable force during earthquakes. Combining flexibilities of cables derived from the elastic material elongation and the assumed parabolic cable shape straightening, a simplified formulation was reached regarding any two conditions (Gimsing and Georgakis 2011):

$$
\varepsilon_{2}-\varepsilon_{1}=\frac{\sigma_{2}-\sigma_{1}}{E}+\frac{\gamma^{2} L^{2}}{24}\left(\frac{1}{\sigma_{1}^{2}}-\frac{1}{\sigma_{2}^{2}}\right)
$$

Where $\varepsilon_{1(2)}$ and $\sigma_{1(2)}$ represent equivalent stain and stress under condition $1 /(2)$ of the cable, respectively; $E$ represents elastic modulus of wire cables which is $1.95 \times 10^{5}$ $\mathrm{MPa} ; \gamma$ represents the density (weight per unit volume) of the cable material; and $L$ represents longitudinal projected length of the cable.

Considering $\sigma_{0}$ and $\varepsilon_{0}$ from deformed equilibrium configuration under dead loads, an equivalent stain- stress relationship of cable material yields:

$$
\begin{aligned}
& \varepsilon=\frac{\sigma-\sigma_{0}}{E}+\frac{\gamma^{2} L^{2}}{24}\left(\frac{1}{\sigma_{0}^{2}}-\frac{1}{\sigma^{2}}\right)+\varepsilon_{0} \\
& \varepsilon_{0}=\frac{\sigma_{0}}{E_{0}}
\end{aligned}
$$

In which, $E_{0}$ is effective elastic modulus of cable material based on Ernst's equivalent elastic modulus under dead loads.

As an example, nonlinear elastic material model for C17 is shown in Fig. 5. It can be seen that at large stress, the tangent modulus of the cable material approaches the linear elastic stiffness while at large axial shortening, the stress and tangent modulus reduce to zero.

Steel bearings were modeled using a zero length element containing an elastic-plastic material model in the longitudinal direction (see Fig. 6) and fixed connections in transverse and vertical directions. Since the bridge was founded by group piles on stiff soil, the foundation of the tower and side piers were set to be fixed, neglecting soilstructure interaction effects. Figure 7 shows the general configuration of the finite

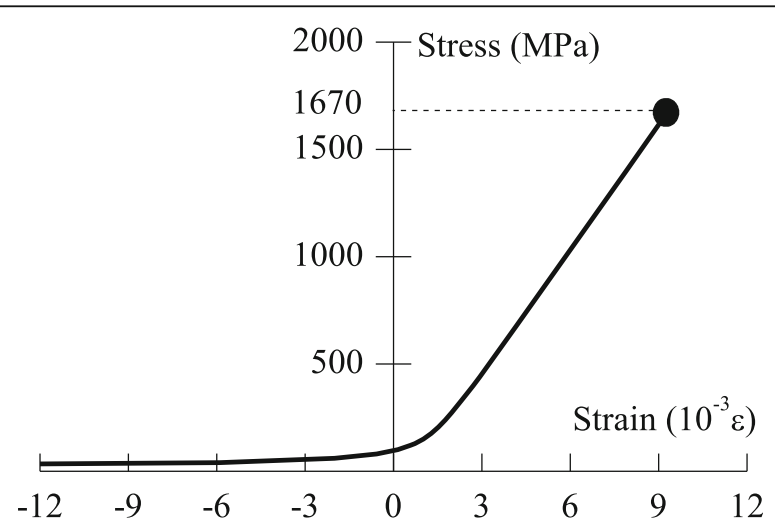

Fig. 5 Stress-strain of the cables 


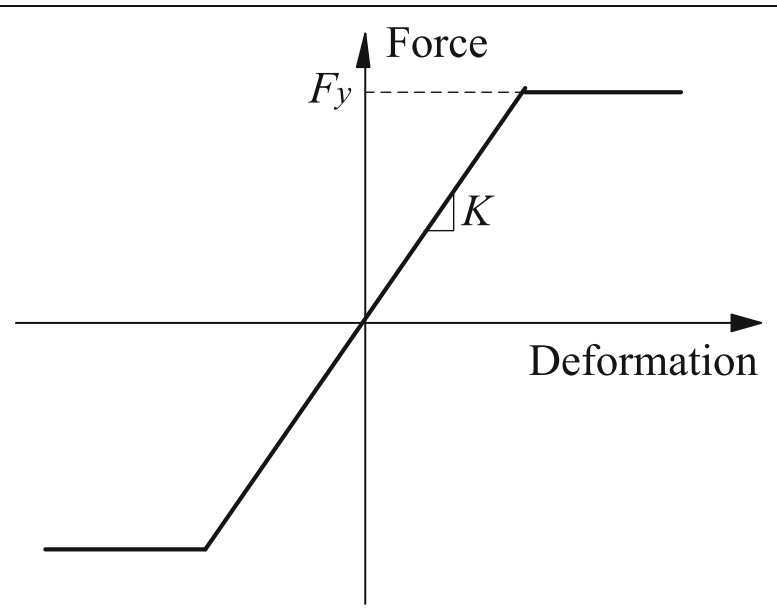

Fig. 6 Force-deformation of the bearings

element model, which it total has 389 nodes, 120 nonlinear beam-column elements, 109 linear elastic beam-column elements and 68 truss elements.

Before nonlinear seismic analysis, dead load was applied to the model prior to nonlinear dynamic analysis so that nonlinear seismic analysis starts from the equilibrium configuration of the structure under dead loads (Ren and Obata 1999; Nazmy and AbdelGhaffar 1990). Direct integration with Newmark-Beta constant acceleration method was used to obtain nonlinear dynamic response of the structure. Rayleigh damping, with $3 \%$ damping ratio assigned to first two modes of the structure, was used to incorporate structural damping matrix.

\subsection{Modal analysis results}

The eigenvalue problem was solved based on the utilization of the tangent stiffness matrix of the bridge at equilibrium configuration from dead loads. Figure 8 shows the modes of the structure that have mass participation ratio larger than 0.01 in the longitudinal direction. The first two modes, referring to longitudinal sliding of the deck and vertical vibration of the deck coupling with the longitudinal vibration of the tower

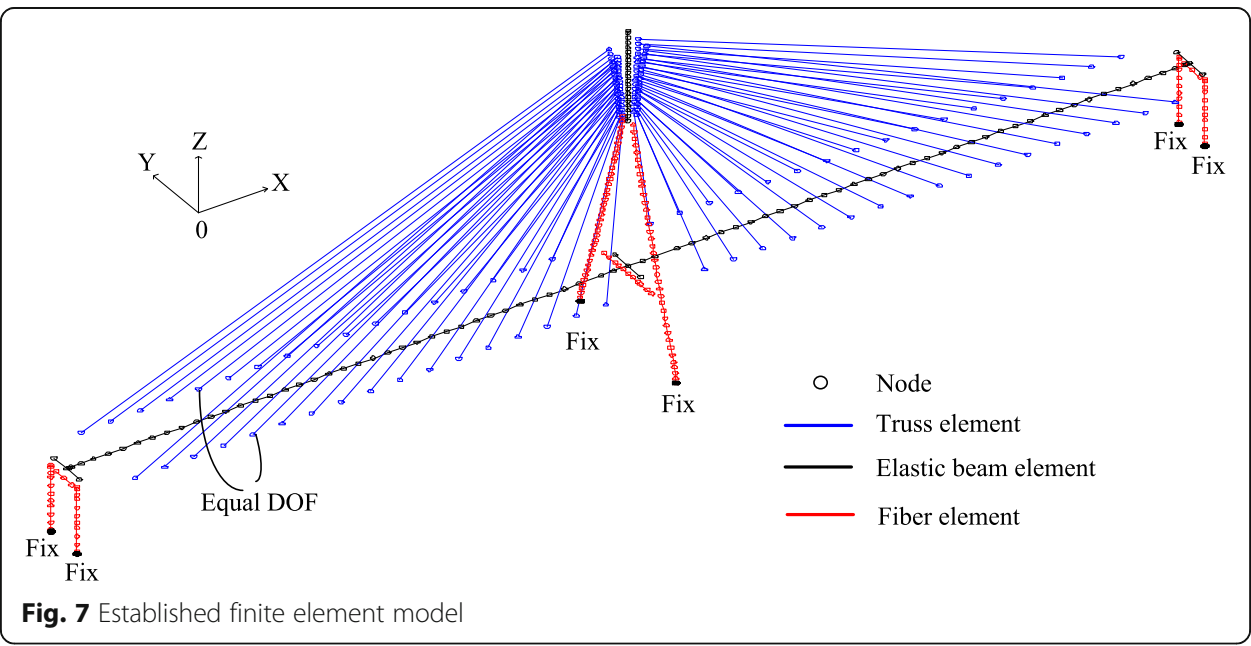




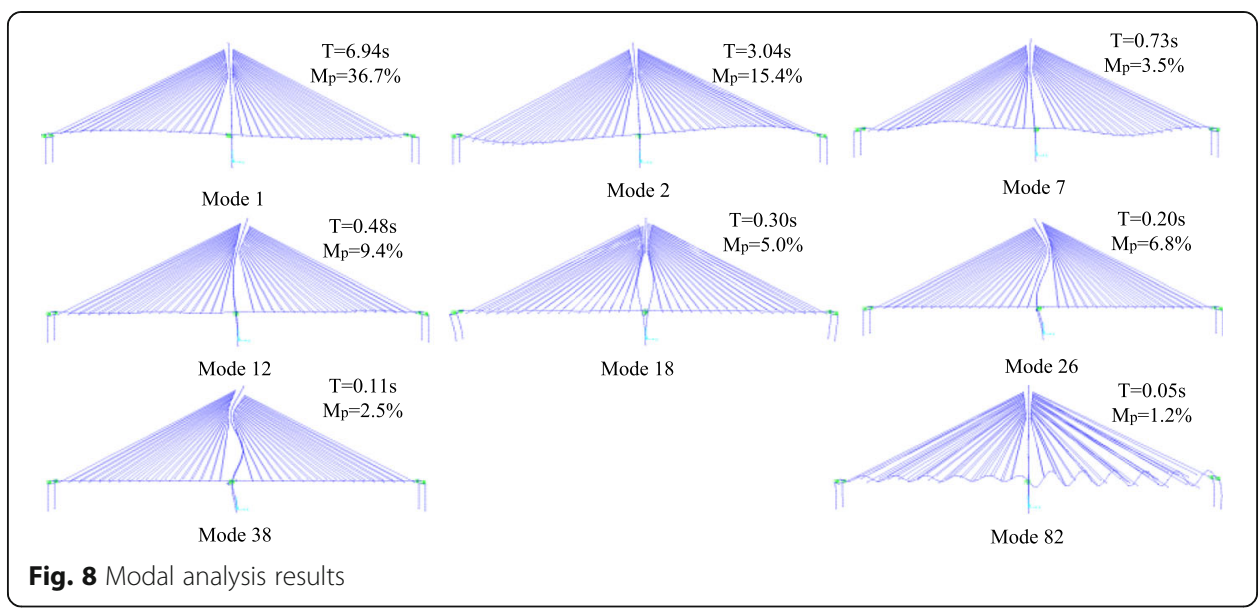

respectively, have much larger mass participation than other modes and totally contribute more than $50 \%$ of mass participation. However, Fig. 8 clearly shows that many other modes, even for very high order modes (like 82th mode), also make a certain contribution to the total mass participation of the structure. This indicates the pronounced high order effects of the case cable-stayed bridge, i.e., the high modes, besides the first two modes, would exert a great influence on the total seismic responses of the bridge. Besides, it is noted that several significant modes, including Mode 2, Mode 7 and Mode 12, involve the coupling of the longitudinal vibration of the tower and the vertical vibration of the deck. Especially for Mode 2, it has the second largest mass participation in the longitudinal direction. It is anticipated that the vertical vibration of the deck would be significantly triggered under longitudinal earthquake excitations.

\section{Earthquake inputs}

Several pulse-type near-field ground motions were recorded from past big earthquakes like 1994 Northridge earthquake in California, the 1995 Kobe earthquake in Japan, and the 1999 Chi-Chi earthquake in Taiwan. Some mathematical formulations (Makris 1997; Mavroeidis and Papageorgiou 2003; Tan et al. 2005; He and Agrawal 2008) were proposed to represent the near-field ground velocity pulses. In this paper, Type B pulse-motions, a simple yet effective formulation proposed by Makris (1997), were used here to characterize pulse-type near-field ground motions. Analytical expressions of type-B pulses for the ground acceleration, velocity and displacement histories are:

$$
\begin{aligned}
& A(t)=\omega_{p} V_{p} \cos \left(\omega_{p} t\right) \quad\left(0 \leq t \leq T_{p}\right) \\
& V(t)=V_{p} \sin \left(\omega_{p} t\right) \quad\left(0 \leq t \leq T_{p}\right) \\
& D(t)=V_{p}\left[1-\cos \left(\omega_{p} t\right)\right] / \omega_{p} \quad\left(0 \leq t \leq T_{p}\right)
\end{aligned}
$$

where $V_{p}$ is the amplitude of the velocity pulse; $T_{\mathrm{p}}$ is the predominant period as well as the duration of the pulse, and $T_{p}=2 \pi / \omega_{p}$.

A set of simulated near-fault pulses were generated here with various pulse periods $\left(T_{p}=0.5 \sim 7.0 \mathrm{~s}\right)$. Figure 9 shows the velocity time histories and $5 \%$ damped acceleration response spectra of generated velocity pulses, namely $T_{p}=0.5,1.0,2.0,3.0,4.0,5.0,6.0$ and $7.0 \mathrm{~s}$. In Fig. 9, the curves were normalized with respect to the amplitude of the 


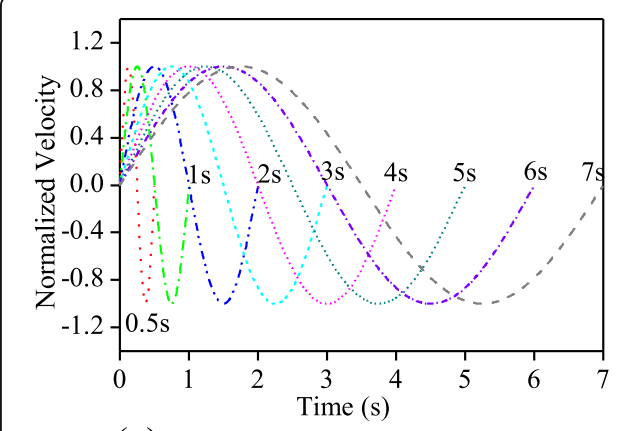

(a) Velocity time histories

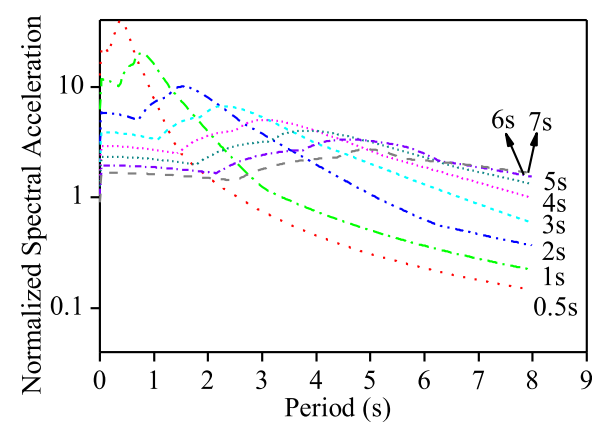

(b) Acceleration response spectra

Fig. 9 Simulated near-fault pulses

velocity pulse $\left(V_{p}\right)$. It can be seen from Fig. 9 that characteristic periods of generated pulses shifted to larger periods as pulse periods $T_{p}$ increased. Spectral accelerations of the pulses with small duration $\left(T_{p}<2 \mathrm{~s}\right)$ were quite large at short periods and rapidly decreased to quite small values at large periods while the pulses with long duration $\left(T_{p}\right.$ $>2 \mathrm{~s}$ ) had relative large spectral accelerations at long structural periods.

It is noteworthy that the horizontal and vertical ground motions are generally recommended in combination to excite cable-stayed bridges in practical engineering. On the other hand, Shrestha (2015) revealed that the vertical ground motions had a limited influence on the seismic response of the cable-stayed bridges. To simplify the analyses for this study, the pulses were applied only in the longitudinal direction of the bridge. Based on the spectral difference of the near-fault pulses, the vibration modes of the cable-stayed bridge are excited at different magnitudes, thus influencing the damage process of the bridge.

\section{Damage states of the structure}

As highlighted by the damage of Chi-Lu Bridge (Chadwell and Fenves 2003) and the shake test results of the cable-stayed bridge model (Yi and Li 2017), several composing parts of cable-stayed bridges, namely the tower, deck and cables might suffer damage during earthquakes. However, since cable-stayed bridges represents the key points transport networks, only the tower was permitted with controllable damage under extreme seismic events for Rion-Antirion Bridge (Combault and Teyssandier 2005) and also in Japanese Code (Japan Road Association 2002). On the other hand, Stonecutters Bridge (Kite et al. 2005) was designed allowing the deck, besides the tower, with minor yielding under a severe earthquake with a return period of 6000 years, but damage of the bridge shall not be such as to endanger emergency traffic or cause loss of structural integrity. For the bridge under study, five damage states of structural components are defined:

(1) The yield state of the tower, which was defined that the steel bar first reached its yield strain at any section of the tower.

(2) The yield state of the deck, which was defined that the steel box first yielded at any section of the deck.

(3) The ultimate state of the tower, which was defined that either confined concrete of tower's section reached the ultimate compressive strength or the reinforcing bars reached the ultimate tension stain. 
(4) The ultimate state of the deck, which was defined that the curvature reached maximum ductility capacity levels at any section of the deck.

(5) The failure of the cables, which was defined that any one of the cables reached its ultimate stress $(1670 \mathrm{MPa})$. For the cables, the elastic-plastic behavior or the rupture of the cables was abandoned during the earthquake, the reason of which will be discussed later.

Based on the damage states of the structural components, two damage states of the whole structure were thus defined: the yield state of the structure and the ultimate of the structure. The yield state of the structure was reached when either the yield state of the tower or the deck occurred while the ultimate state of the structure was when either the ultimate state of the tower, the deck or cables occurred. Before the yield state of the structure, there was no structural damage during the earthquake since material nonlinearity was avoided and no repair was needed after earthquake. After the yield state of the structure, some structural damage and residual displacement was anticipated so that possible post-earthquake repair was needed after earthquake. Despite that, structural integrity was guaranteed during the earthquake and the access to emergency traffic was provided after earthquake. After entering into the ultimate state of the structure, the structure might be able to sustain much larger earthquakes without collapse, but emergency traffic was endangered after the earthquake and thus more permitted damage to the structure was abandoned.

Under a particular earthquake input, it's desired to determine whether the yield of the structure was attributed from the yield of the tower or the yield of the deck. Yield indexes were defined for the tower, the deck and cables as follows. In particular, $Y I_{c}$ was defined here in case that the yield of the cables appeared prior to the yield of the tower or the yield of the deck. The yield state of the structure was reached when $Y I=1$.

$$
\begin{aligned}
& Y I_{t}=\max \left(\frac{\phi_{t}}{\phi_{t y}}\right), \quad Y I_{d}=\max \left(\frac{\phi_{d}}{\phi_{y d}}\right), Y I_{c}=\max \left(\frac{F_{c i}}{F_{u i}}\right) \\
& Y I=\max \left(Y I_{t}, \quad Y I_{d}, \quad Y I_{c}\right)
\end{aligned}
$$

where $Y I_{t}, Y I_{d}$ and $Y I_{c}$ were the maximum yield indexes of the tower, the deck and cables, respectively; $\phi_{t}$ and $\phi_{t y}$ were the curvature and yield curvature of one tower section; $\phi_{d}$ was the maximum curvature of all the deck sections; $\phi_{y d}$ was the yield curvature, and $\phi_{y d}=0.00096 ; F_{c i}$ and $F_{u i}$ were the maximum tension force and ultimate tension force of Cable i ( $\mathrm{i}=1 \sim 17$ ); YI the yield index of the structure.

Similarly, ultimate indexes were also defined for the tower, the deck and cables. The ultimate state of the structure was reached when $U I=1$.

$$
\begin{aligned}
& U I_{t}=\max \left(\frac{\phi_{t}}{\phi_{u t}}\right), U I_{d}=\max \left(\frac{\phi_{d}}{\phi_{u d}}\right), U I_{c}=Y I_{c} \\
& \mathrm{UI}=\max \left(U I_{t}, U I_{d}, U I_{c}\right)
\end{aligned}
$$

Where $U I_{t}, U I_{d}$ and $U I_{c}$ were the failure indexes of the tower, the deck and cables, respectively; $\phi_{u t}$ was the maximum curvature of one tower section; $\phi_{u d}$ was the ultimate curvature, and $\phi_{u d}=0.0167 ; U I$ was the ultimate index of the structure. 
For each pulse, the acceleration waves were applied to excite the cable-stayed bridge from low to high intensity. The yield state and the failure state of the bridge are evaluated based on the damage state of different structural components under earthquake inputs with the same amplitude.

\section{Yield state of the bridge}

Figure 10 shows the yield indexes at the yield state of the structure $(Y I=1)$. It is observed that except $T_{p}=4 s$, the yield of the tower appeared first for most cases. This agrees with the expectation of Japanese code that permissible damage of cable-stayed bridges occurred at the tower. However, when $T_{p}=4 s$, the yield of the deck occurred prior to the yield of the tower. As $T_{p}$ become larger, there was a steady increase of yield index of the deck $\left(Y I_{d}\right)$ when $T_{p}<4 s$ while a gradually decrease when $T_{p}>4 s$. For cases of $2 s \leq T_{p} \leq 5 s$, the $Y I_{d}$ was all larger than 0.8 , which means the deck was quite vulnerable to damage as period of the pulse was within this period. For the cables, the yield index was all below 1, showing the cables perform well at the yield state of the structure. However, $Y I_{c}$ reached more than 0.8 for $T_{p}=1 s$ and $T_{p}=3 s$ so that the seismic response of the cables should also be paid attention to.

In order to reveal the influence of $T_{p}$ on $Y I_{t}, Y I_{d}$ and $Y I_{c}$, the seismic response of the tower, the deck and cables were investigated as follows.

\subsection{Tower response}

Figure 11 shows yield index curve of the tower at the yield state of the structure. Unlike normal uniform reinforced concrete columns whose vulnerable section locates at the bottom of the column, the maximum steel stain of the tower occurs at the middle tower, due to the decreasing cross section along with the tower height. For all cases, the sections where steel first yields might occur along the most part of middle tower, depending on pulse period $T_{p}$. Pulse period $T_{p}$, by reflecting the frequency characteristics of the input pulses (see Fig. 9), affects relative contribution of multiple modes to the total response. For this particular bridge, the first yielding section tends to decrease

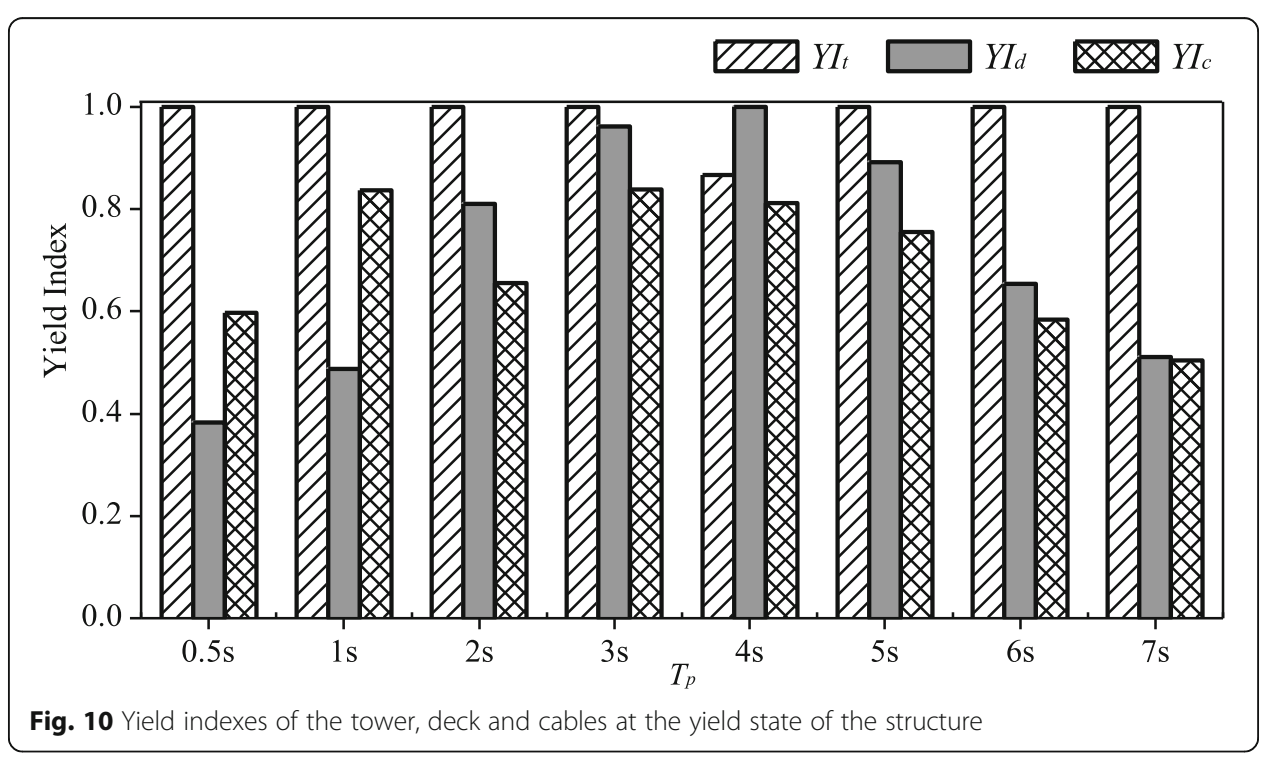



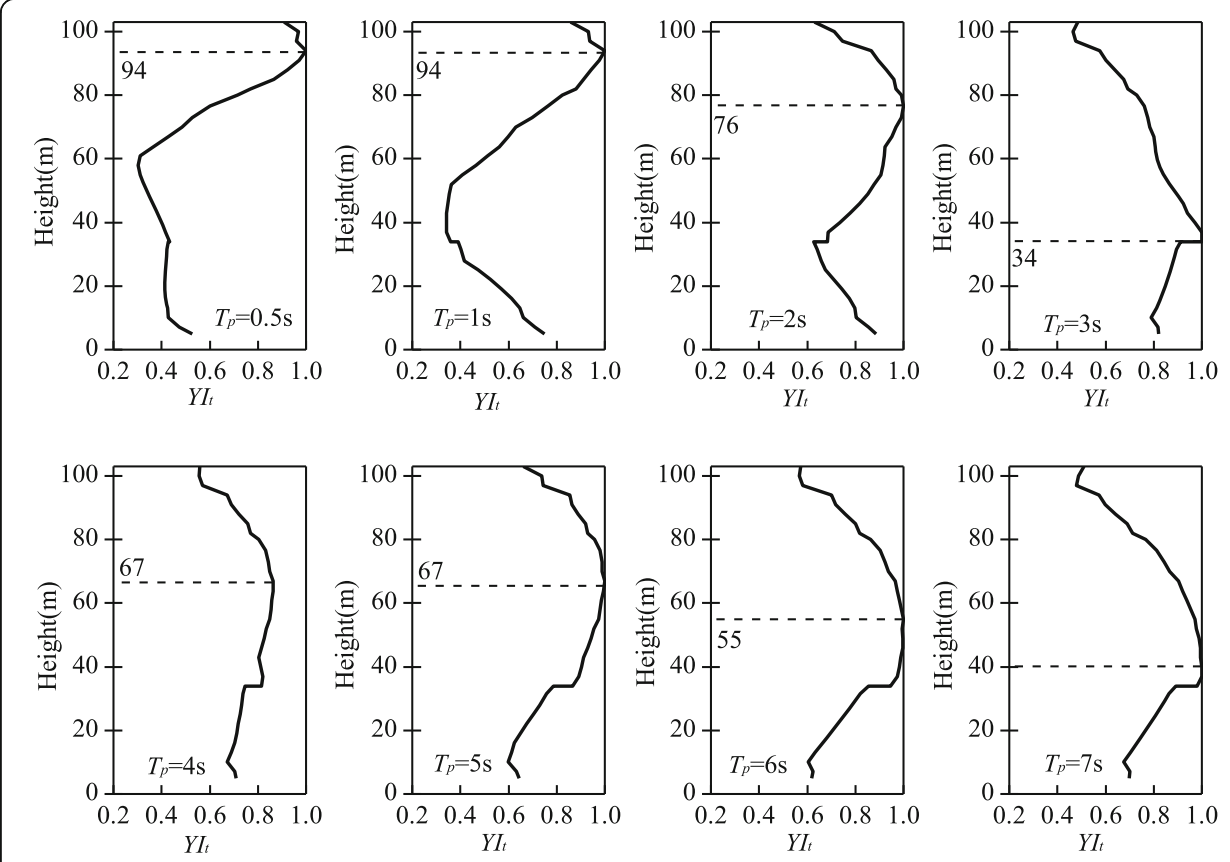

Fig. 11 Yield index curve of the tower at the yield state of the structure

from the height of $97 \mathrm{~m}$ to $40 \mathrm{~m}$ as $T_{p}$ increases from $0.5 \mathrm{~s}$ to $7 \mathrm{~s}$, except for $T_{p}=3 \mathrm{~s}$ where yield section first occurs at bottom of the middle tower $(34 \mathrm{~m})$. Thus, the damage section of the tower during the pulse-type earthquake can't be previously set only after input ground motions was determined.

\subsection{Deck response}

Figure 12 shows the yield index curve of the deck along the deck length at the yield state of the structure. In Fig. 12, the contribution of pure seismic response to the yield index (seismic index), which was obtained by the yield index minus the ratio of absolute deck curvature at dead load to $\phi_{y}$, was also presented. In addition, Fig. 12 includes deck moment curvature of first and second mode from the modal analysis, which was normalized to the maximum seismic index.

The seismic response of the deck was attributed from complex participation of several modes of the bridge and Fig. 12 clearly shows that the contribution of each modes was affected by pulse period $T_{p}$. The seismic index curve along the deck length was almost alike for most cases except $T_{p}=0.5 \mathrm{~s}$ or $T_{p}=1 \mathrm{~s}$. For the cases of $T_{p}=0.5 \mathrm{~s}$ and $T_{p}$ $=1 \mathrm{~s}$, since pulse period was close to vibration period of higher modes other than Mode 1 and Mode 2, higher modes made great contribution to the total response so that the deck seismic index curvature was quite different from Mode 1 or Mode 2. As $T_{p} \geq 2 \mathrm{~s}$, since the spectral acceleration become quite large for Mode $1(\mathrm{~T}=6.94 \mathrm{~s})$ and Mode 2 $(\mathrm{T}=3.04 \mathrm{~s})$ with largest mass participation ratios in the longitudinal direction, the contribution of Mode 2 and Mode 1 becomes dominate. Especially for the cases of $T_{p}=$ $2 s \sim 5 s$ when the pulse period was close to the vibration period of Mode 2, the Mode 2 had resonant response with the pulse that the vibration of the deck was largely excited and deck seismic index curve was quite close to Mode 2. This explains why $Y I_{d}$ was 


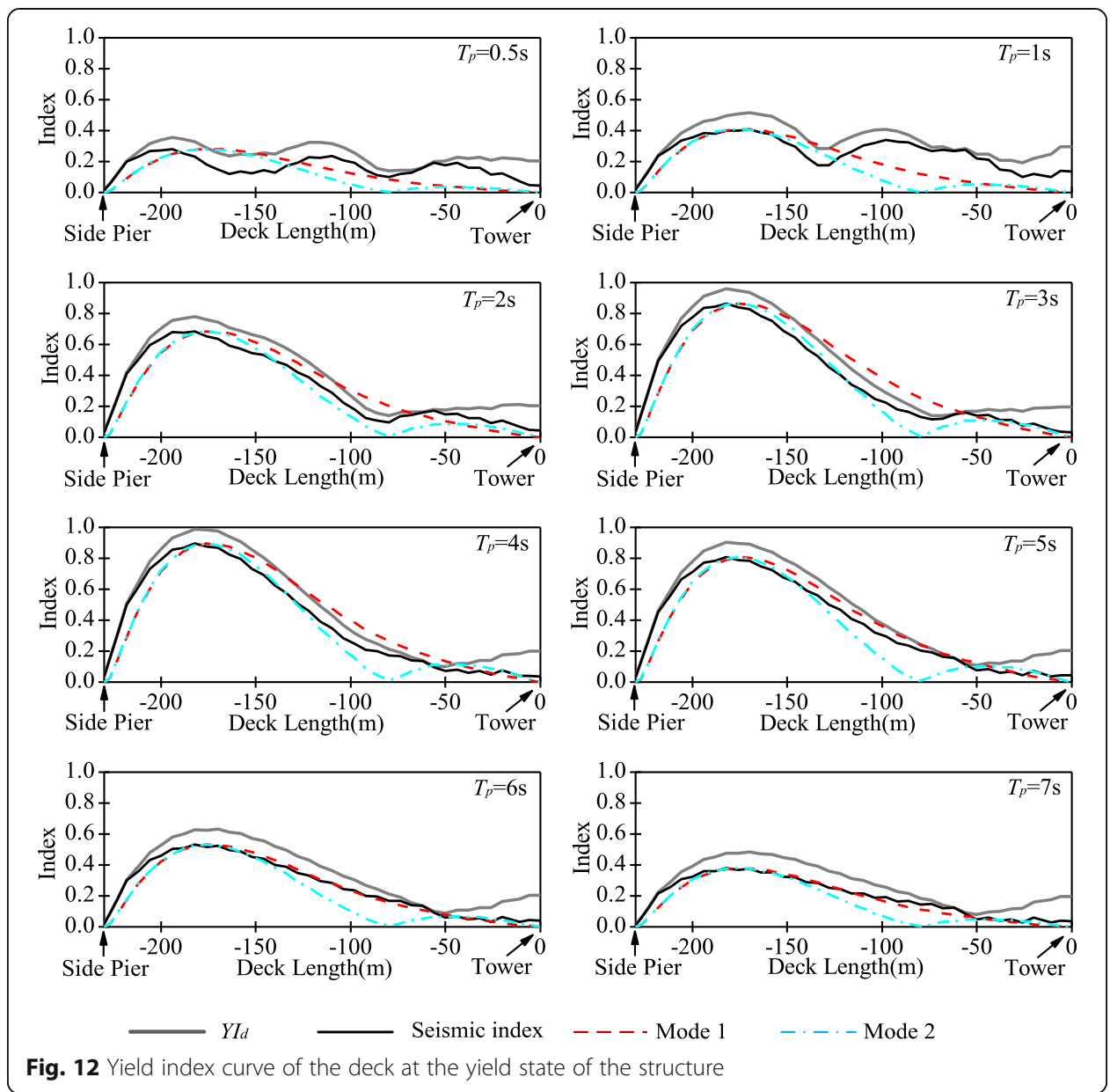

larger than 0.8 within these cases. As $T_{p}$ increased to $6 \sim 7 \mathrm{~s}$, on the other hand, the pulse period gets so close to vibration period of Mode 1 that the most contribution to deck response comes from Mode 1. Thus, the seismic index curve becomes close to Mode 1 . However, the section of the deck with the largest yield index was at the section around $180 \mathrm{~m}$ away from the tower for all cases.

\subsection{Cable response}

Figure 13 shows the yield index curves of the cables at the yield state of the structure. Similar to Fig. 12, Fig. 13 includes seismic index, which was defined as the contribution of pure seismic response to the yield index and was obtained by the yield index minus the ratio of cable forces at dead load to the ultimate force. In addition, Fig. 13 also presents deck moment curve of first and second modes from the modal analysis, which was normalized to the maximum seismic index.

Similar to the deck response, pulse period $T_{p}$ influenced the seismic index curve as follows:

As $T_{p}=0.5 \mathrm{~s}$ or $T_{p}=1 \mathrm{~s}$, higher modes other than Mode 1 and Mode 2 contribute intensively to the cable forces. Thus, seismic index curve was quite distinguished from curve of Mode 1 or Mode 2 and the most vulnerable cables were C3 C4. As $T_{p} \geq 2 \mathrm{~s}$, 

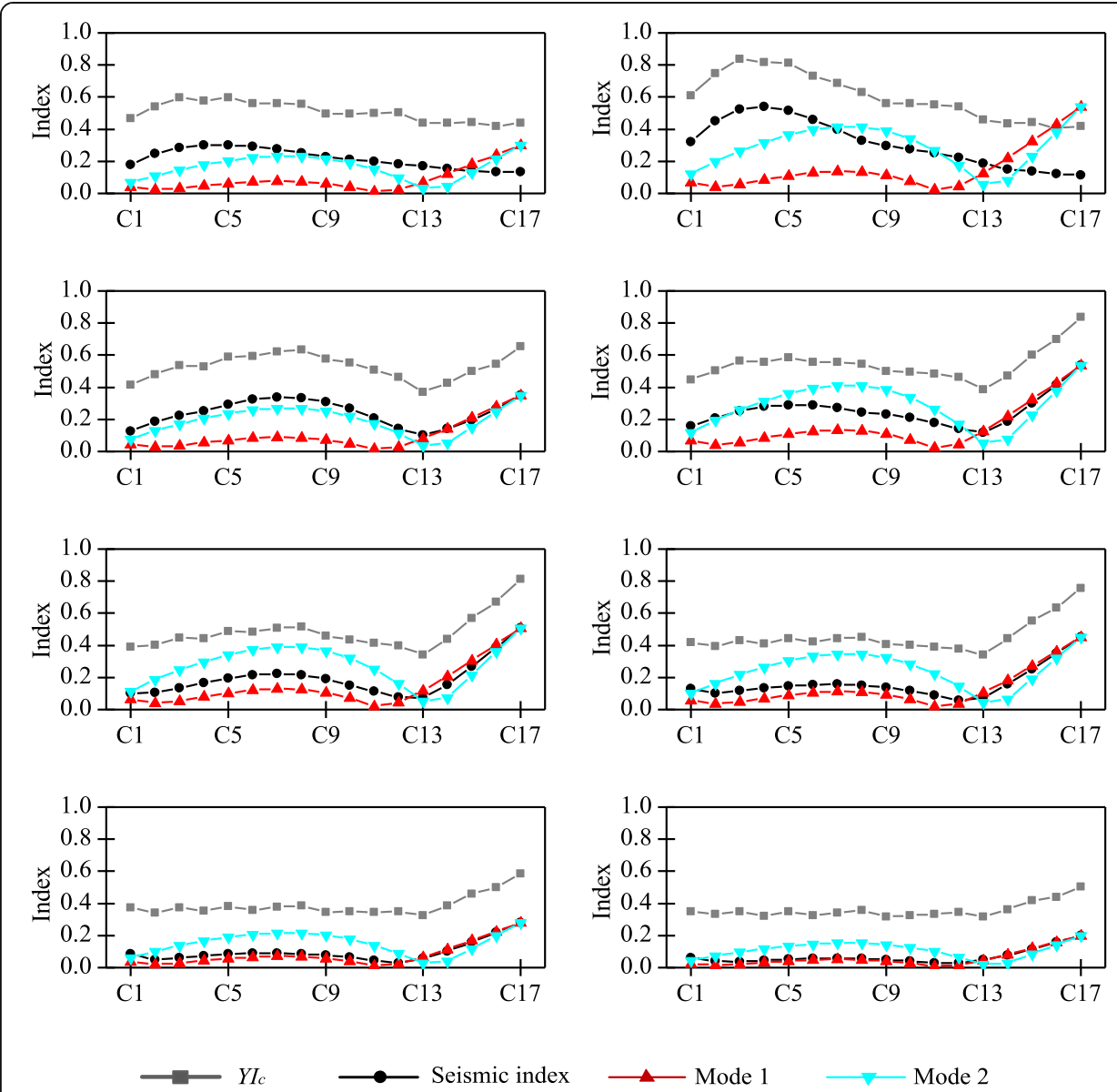

Fig. 13 Yield index curve of the cables at the yield state of the structure

the contribution of Mode 1 and Mode 2 to the total seismic index increased and the most vulnerable cables shifted to $\mathrm{C} 17$. For the cases $T_{p}=2 s \sim 3 s$, the seismic index curve resembled to that of the Mode 2 since the pulse period was close to vibration period of this mode. But for the cases of $T_{p} \geq 4 s$, the seismic index become more resembling to Mode 1.

\section{Ultimate state of the bridge}

Figure 14 shows the ultimate indexes of the tower, deck and cables at the ultimate state of the structure $(U I=1)$. Unlike the yield state of the structure that the tower first yielded for most cases, the cables were the most vulnerable components except for $T_{p}=$ $0.5 \mathrm{~s}$ and $T_{p}=7 \mathrm{~s}$ where the tower reached ultimate state first. $U I_{t}$ was quite sensitive to $T_{p}$. As $T_{p}$ increased, the $U I_{t}$ first decreased to quite low value and then increased. Especially for the cases of $3 s \leq T_{p} \leq 5 s, U I_{t}$ was relatively small since the vibration of the deck and cables was largely excited by the pulses. For all the cases, the $U I_{d}$ was smaller than 0.2 , showing that the deck went through small inelastic deformation despite first yielding for some cases.

The seismic response of the tower, deck and cables at the ultimate state of the bridge was investigated as follows. 


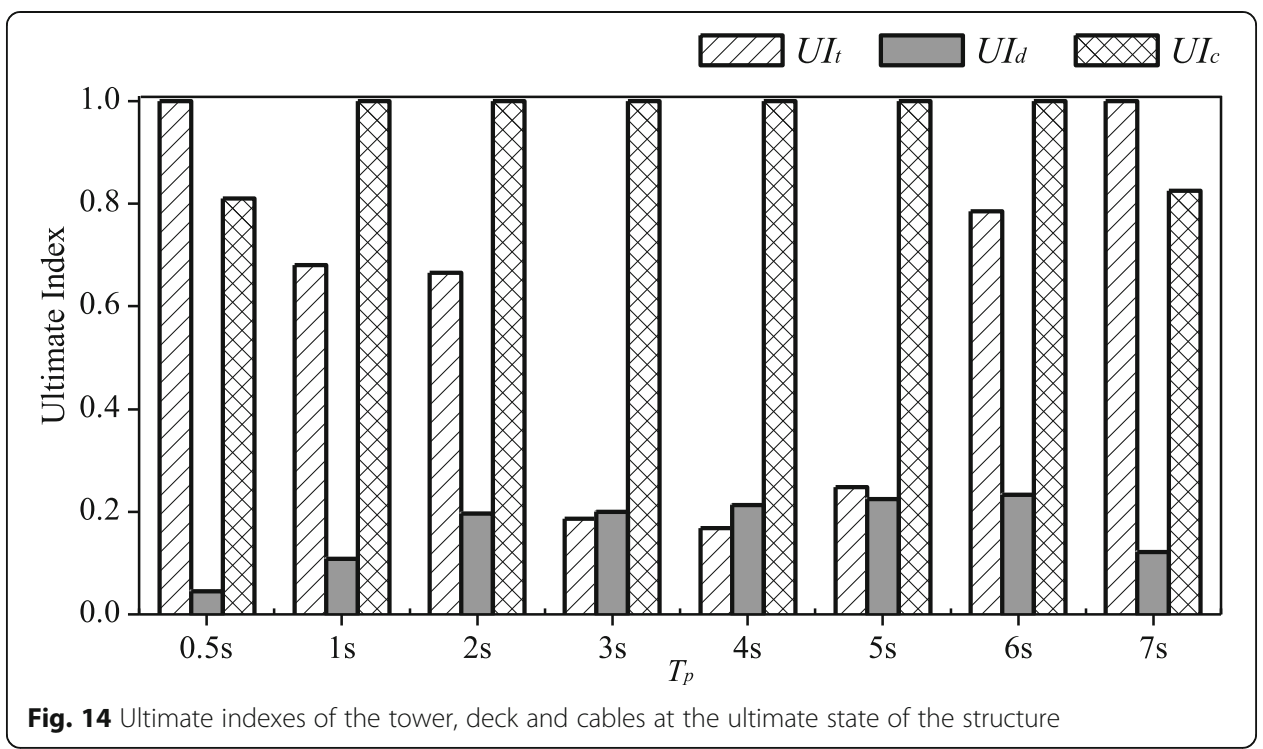

\subsection{Tower response}

Figure 15 shows ultimate index curve of the tower at the ultimate state of the structure. As $T_{p} \leq 2 s$, the tower bottom had the largest ultimate index while relatively large curvature also occurred at top of middle tower. However, the ultimate index curves were quite distinguished for each case due to relative contribution of higher modes. As $T_{p} \geq$ $3 s$ where the first two modes were largely excited, the ultimate index curves, on the other hand, were quite alike for all cases despite of variable amplitudes. The largest curvature occurred at the bottom of middle tower while the curvature at the tower bottom and top of middle tower was quite small. Attention should be paid that, unlike common bridge piers where inelastic deformation concentrated at one or several locations, all sections of the tower might go through large inelastic deformation (like $T_{p}=$ $0.5 s$ ), owing to the reduced cross section along the tower height. Therefore, seismic design details required for ductile behavior should be applied for the whole tower.

\subsection{Deck response}

Figure 16 shows the ultimate index curve of the deck section at the ultimate state of the structure. Except $T_{p}=0.5 \mathrm{~s}$ that the deck kept in elastic range, some inelastic deformation was observed at the deck section for $T_{p} \geq 1 \mathrm{~s}$. The section with inelastic deformation spreads within a large region from about $-200 \mathrm{~m}$ to $-150 \mathrm{~m}$ and the largest deformation occurred at around $-180 \mathrm{~m}$. Due to the large contribution of the Mode 2, the inelastic deformation was quite large for cases of $T_{p}=2 s \sim 6 s$ with the maximum curvature ductility factor of around 4 .

\subsection{Cable response}

Figure 17 shows the ultimate index of cables at the ultimate state of the structure. Clearly, pulse period $T_{p}$ determined the ultimate index curve and the most vulnerable cables during the excitation. As $T_{p} \leq 2 s$, the ultimate index curves were quite distinguished from each other and the most vulnerable cables might be either $\mathrm{C} 3 \sim \mathrm{C} 5$ or 

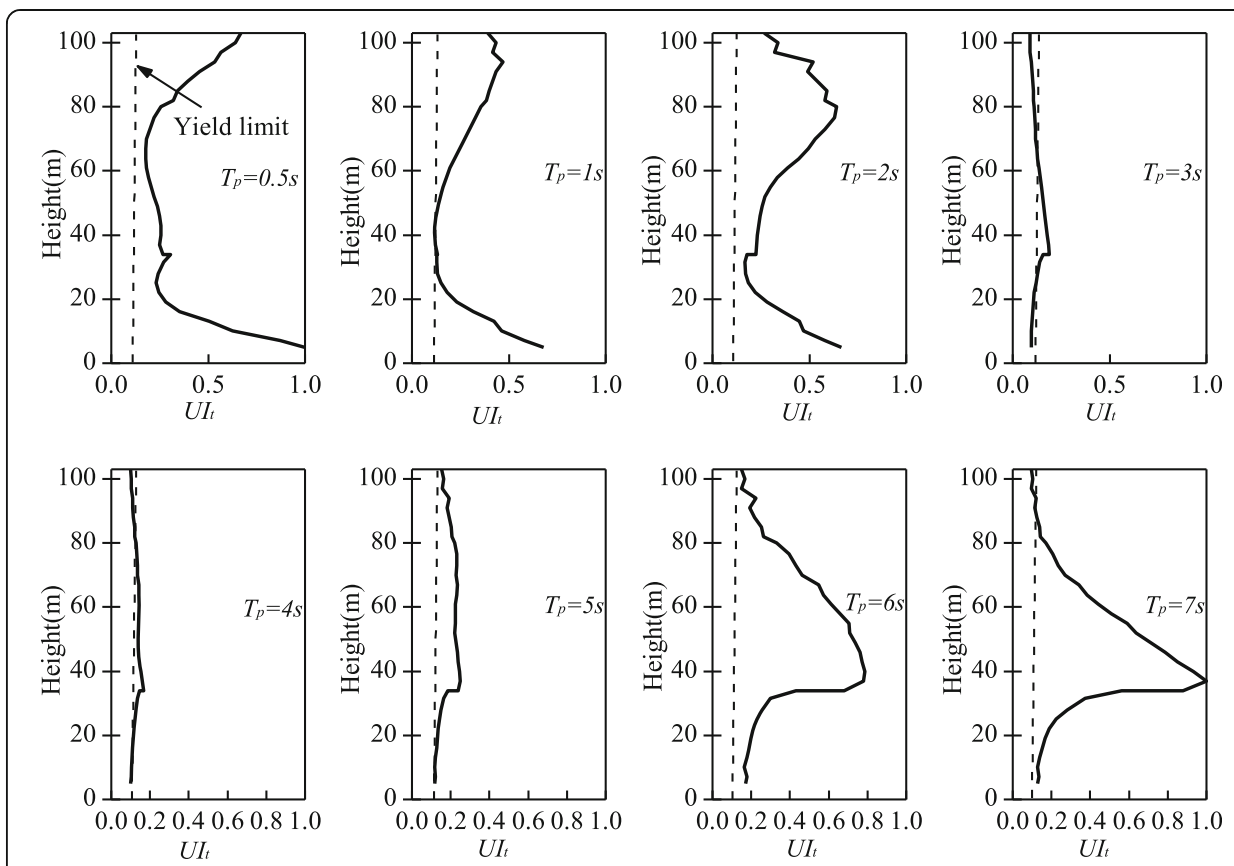

Fig. 15 Ultimate index curve of the tower at the ultimate state of the structure

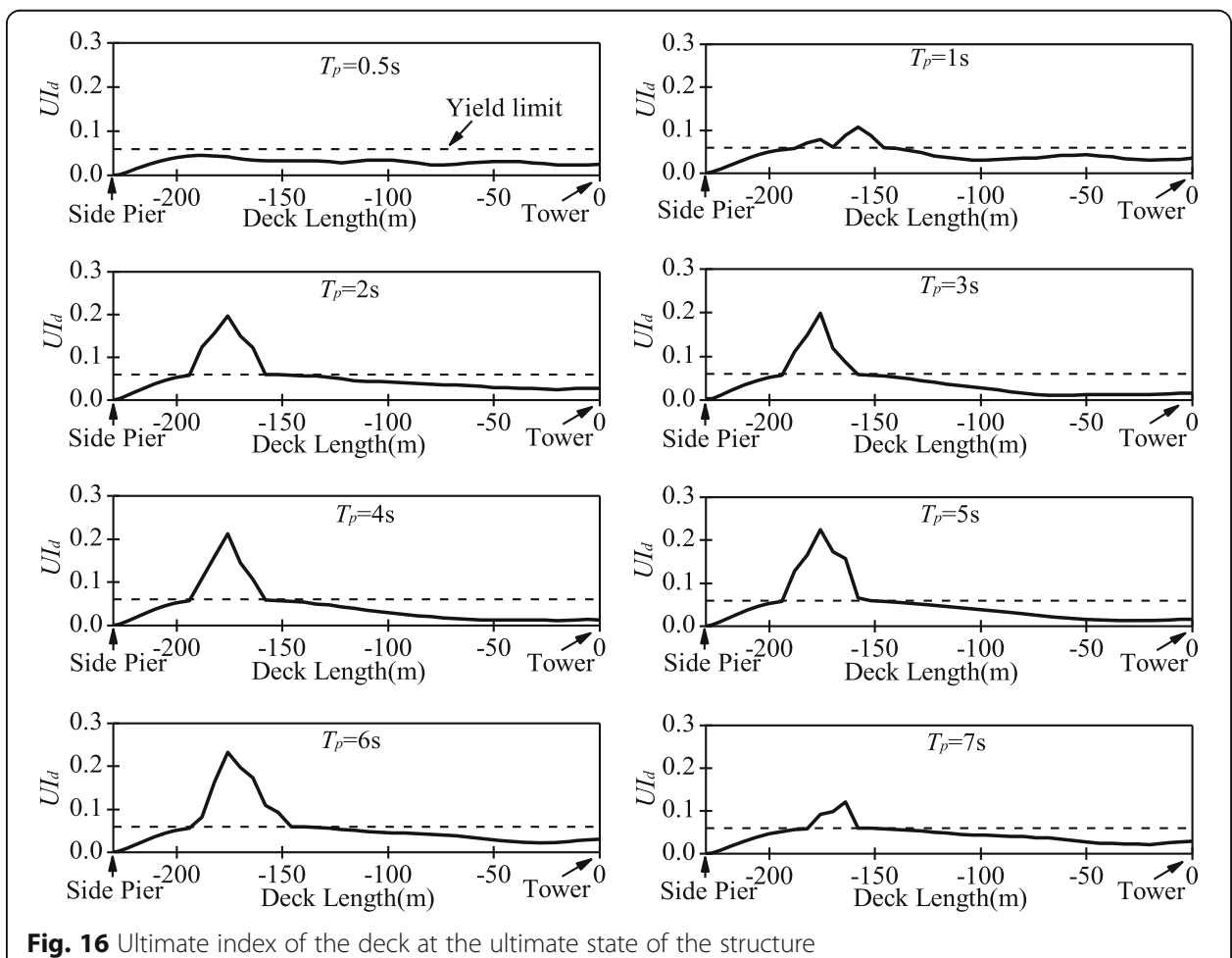

Fig. 16 Ultimate index of the deck at the ultimate state of the structure 


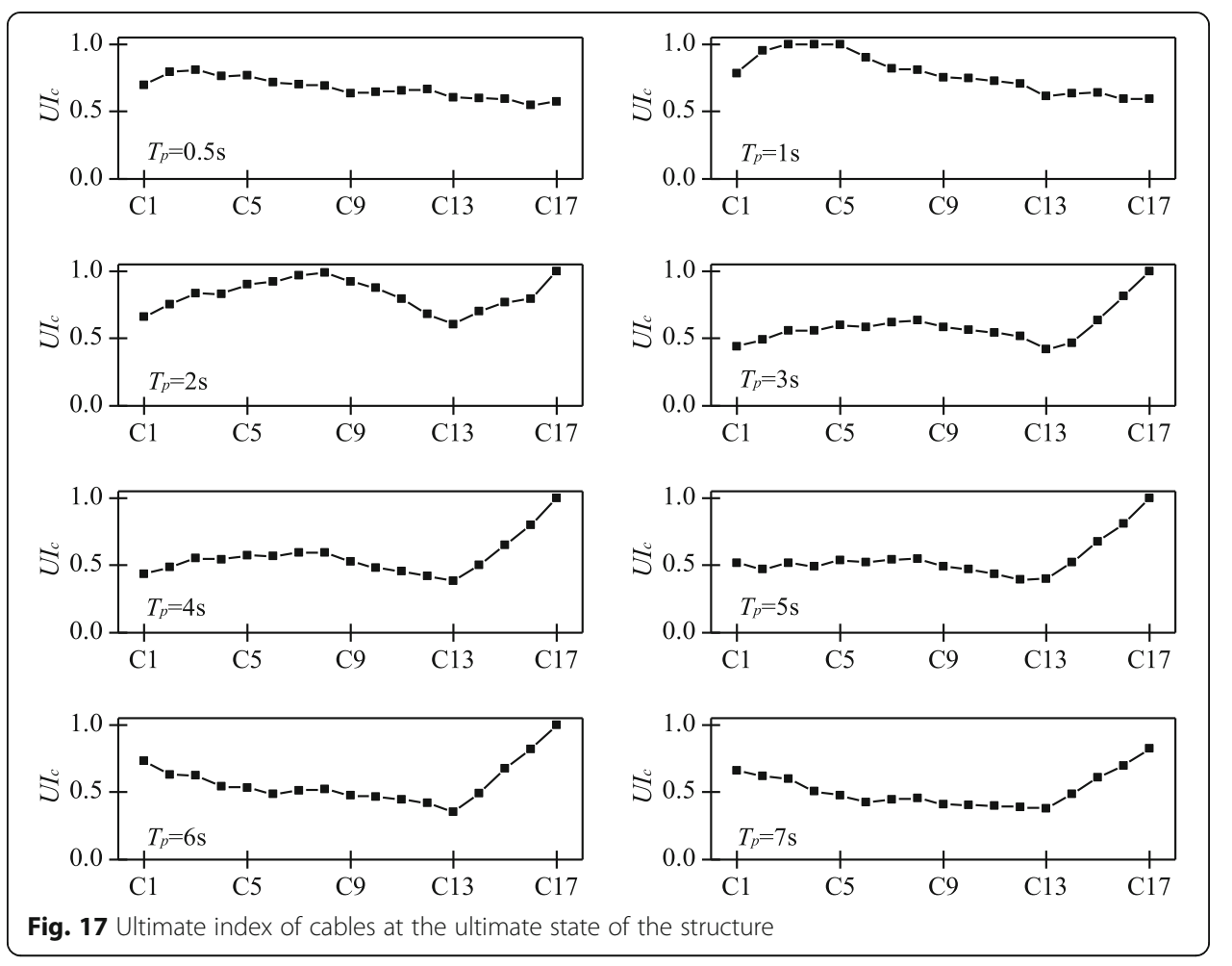

C17. But for cases of $T_{p} \geq 3 s$, all cases had the similar ultimate index curves with maximum index located at $\mathrm{C} 17$, in accordance with the shape of Mode 1 and Mode 2.

For cable-stayed bridges under dead loads, cables normally sustained the stress far less than its ultimate stress. For example, the cable stress of the bridge under study was about $1 / 3$ of its ultimate stress at dead load state. Despite that the failure of a stay cable, possibly causing by corrosion, abrasion or fretting fatigue, increased the axial stress of remaining cables, the structure kept similar dynamic behavior of that without the broken stay (Mozos and Aparicio 2011) since no more cables failed. However, one can see from Fig. 17 that as one of the cables reached its ultimate tension force under pulse excitation, the cables nearby also sustained large tension forces. Once one of the cables failed during the earthquake, nearby cables might also fail due to the increased axial force shifting from the failure cable. This chain effect gradually caused the failure of the entire cable system and as a result the collapse of the structure. Therefore, this paper considered the failure of one cable during earthquakes to be the ultimate state of the structure.

\section{Damage process of the structure}

Figure 18 shows the ductility factor development of the tower and the deck after the yield of the structure where the hollow circle depicted the ultimate state of the structure. In Fig. 18, the ductility factor of the tower $\mu_{t}$ and the ductility factor of the deck $\mu_{d}$ were calculated as follows:

$$
\mu_{t}=\max \left(\frac{\phi_{t}}{\phi_{t y}}\right), \mu_{d}=\frac{\phi_{d}}{\phi_{y d}}
$$

Where $\phi_{t}, \phi_{t y}, \phi_{d}$ and $\phi_{y d}$ were defined at (7). It can be seen that as $T_{p}=0.5 s$, the damage of the structure concentrated at the tower while the deck remained 

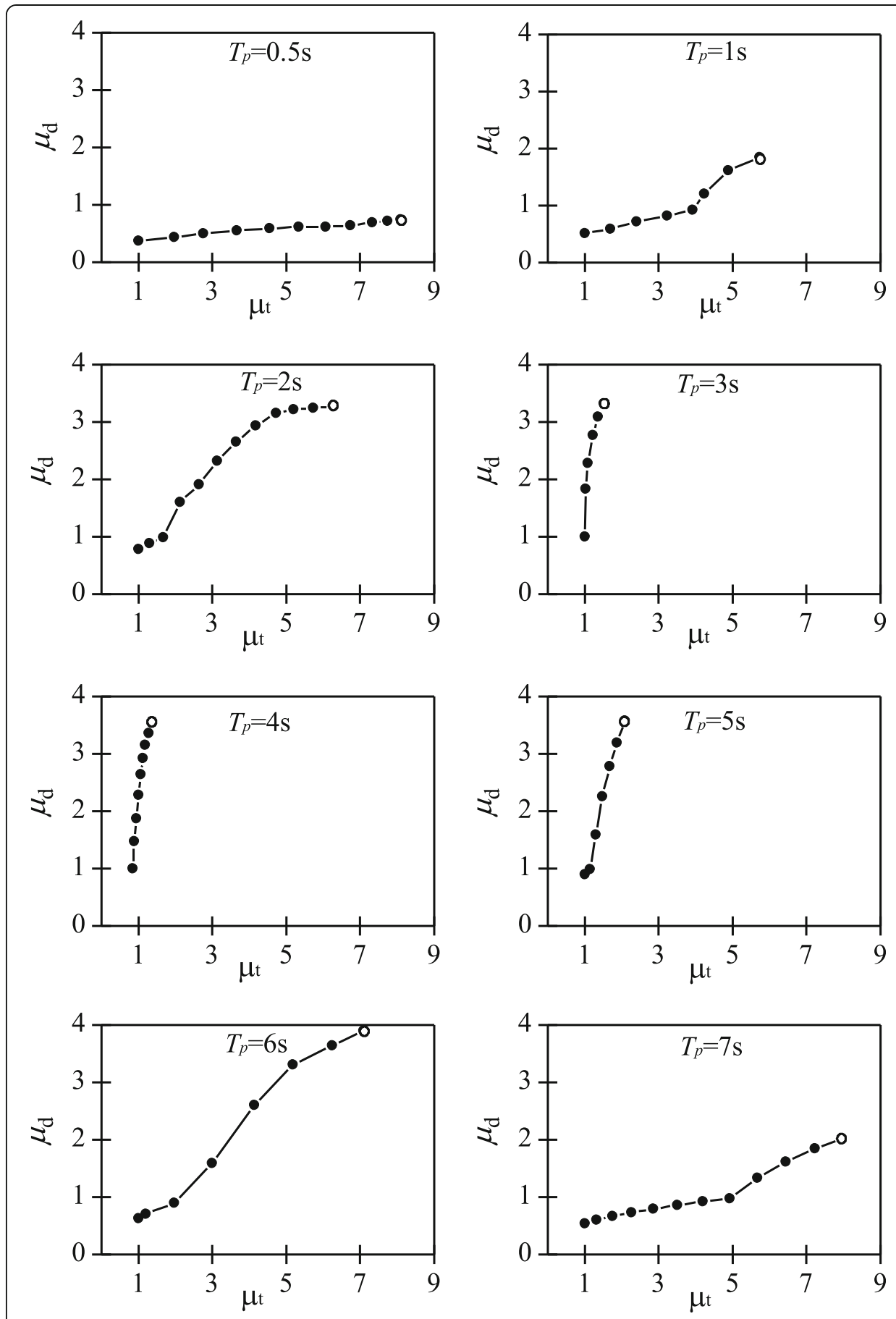

Fig. 18 Relative ductility development between the tower and the deck

undamaged. As for $T_{p}=1 \sim 2 s$ and also $T_{p}=6 \sim 7 s$, the damage occurred and developed at the tower but the deck also might suffer some damage. Before the deck yielded, $\mu_{t}$ almost linearly increased as the $\mu_{d}$ increased at a quite slow rate; but after deck yielded, $\mu_{t}$ increased faster, showing the yielding of the tower provided no relief of the deck from seismic damage. As for $T_{p}=3 \sim 5 s$, the damage accumulated at the deck despite that slight damage of the tower was also observed. This agrees with the observation 
from Figs. 10 and 14 that the components with the severest damage shift from the tower to the deck within these periods. The reason is that as the pulse period ( $T_{p}=$ $3 \sim 5 s)$ gets close to the vibration period of Mode $2(T=3.04 \mathrm{~s})$, Mode 2, depicting the vertical vibration mode of the deck with the second largest mass participation in the longitudinal direction, is extensively excited. As a result, the vibration of the deck as well as the cable force variation is significantly triggered, leading to large seismic responses of the steel deck which suffers from section yielding and causes the structural failure finally. Outside of $T_{p}=3 \sim 5 s$, either the first mode ( $T=6.94 \mathrm{~s}$ ) or the high modes $(T<3 \mathrm{~s})$ are significantly excited where the tower vibrations dominate so that the damage of the bridge concentrates on the tower sections which finally suffer complete failure.

\section{Conclusions}

This paper focuses on the longitudinal damage of a cable-stayed bridge under nearfault ground motions. For this purpose, a nonlinear finite element model of the bridge was developed and a set of simulated near-fault ground motion pulses were used to excite the structure. The seismic response of the tower, deck and cables was evaluated at the yield and ultimate state of the structure. Following conclusions are drawn.

(1) The yield state of the structure was defined that either the section of the tower or the deck reached its yield limit while the ultimate state of the structure was that the tower or the deck reached its ultimate limit, or the cables reached ultimate stress. Especially, as one of the cables reached its ultimate stress under pulse excitations, the cables nearby also sustained large tension forces. Once one of the cables failed during the earthquake, nearby cables might consequently fail due to the increased axial force shifting from the failure cable. Thus, the failure of cables during an earthquake was considered to be the ultimate state of the structure.

(2) The period of the pulses determined the relative contribution of different modes of the structure and thus affected the damage process of the structure. As $T_{p}<2 \mathrm{~s}$, higher modes other than Mode 1 and Mode 2 greatly contributed and the damage mainly occurred at the tower. As $T_{p}>2 \mathrm{~s}$, the response of the structure mainly results from Mode 1 and Mode 2. In particular, when $T_{p}=3 \sim 5 \mathrm{~s}$ which was close to the period of first vertical vibration of the deck (Mode 2), the responses of the deck and cables were largely excited so that the deck might yield prior to the yield of the tower, and the deck suffered most of the damage despite of the yielding of the tower. Outside of $T_{p}=3 \sim 5 \mathrm{~s}$, the tower suffered from the most severe seismic damage and failed prior to other components.

(3) Unlike conventional piers of the bridges which have only one or several damage regions, the sections of the whole tower legs might go through ductile behavior so that seismic design details should be applied for the whole tower. For the deck, damaged section concentrated at a wide region located at about $150 \mathrm{~m}$ to $200 \mathrm{~m}$ away from the tower with the maximum curvature ductility factor less than 4 . The most vulnerable cables might be $\mathrm{C} 3 \sim \mathrm{C} 5$ or $\mathrm{C} 17$ depending on the pulse period.

The above conclusions highlight the importance of the deck and the cable design for cable-stayed bridges in near-field regions, especially for the case that the pulse period is 
close to that of the first deck vertical vibration. For instance, the anchorage of the cable should be strengthened to avoid premature anchorage failure of the cable and the steel deck stiffened to prevent local buckling. A limitation of this study is that only artificial pulses are discussed, which have slightly different spectral characteristics compared to typical history records. Future studies are needed to investigate the influence of the real near-field records on the damage process of cable-stayed bridges. Meanwhile, under extreme conditions, the traffic loads, which was not considered in this study, would exert a large influence whereas they are not considered in this study. Further investigations are needed on this issue.

Acknowledgements

Not applicable.

\section{Authors' contributions}

Jiang Yi carried out the molecular genetic studies, participated in the sequence alignment and drafted the manuscript De'en Yu conceived of the study, and participated in its design and coordination and helped to draft the manuscript.

All authors read and approved the final manuscript.

Funding

This research is supported by the University Scientific Research Project of Guangzhou Education Bureau (No. 202032797).

\section{Availability of data and materials}

Supplementary data to this article can be received upon request via yijiang@gzhu.edu.cn.

\section{Competing interests}

The authors declare that they have no known competing financial interests or personal relationships that could have appeared to influence the work reported in this paper.

\section{Author details}

${ }^{1}$ College of Civil Engineering, Guangzhou University, Guangzhou, China. ${ }^{2}$ China Highway Engineering Consultants Corporation, Haikou, Hainan, China.

Received: 10 November 2020 Accepted: 17 January 2021

Published online: 25 February 2021

\section{References}

California Department of Transportation. Caltrans seismic design criteria, 1.7[S], USA, 2013

Calvi GM, Sullivan TJ, Villani A (2010) Conceptual seismic design of cable-stayed bridges. J Eartha Eng 14(8):1139-1171

Camara A, Astiz MA (2012) Pushover analysis for the seismic response prediction of cable-stayed bridges under multidirectional excitation. Eng Struct 41(3):444-455

Chadwell CB, Fenves GL (2003) Near source earthquake effects on the ji lu cable-stayed bridge in the 21 September 1999 chi-chi taiwan earthquake. In: Roddis W (ed) Community workshop on computational simulation and visualization environment for NEES. National Science Foundation, Univ. of Kansas, Lawrence

Chadwell, C.B., Imbsen \& Associates, (2002), "XTRACT - cross section analysis software for structural and earthquake engineering". http://www.imbsen.com/xtract.htm

Chang KC, Mo YL, Chen CC et al (2004) Lessons learned from the damaged Chi-Lu cable-stayed bridge. J Bridg Eng 9(4):343352

Combault J, Pecker A, Teyssandier J-P, Tourtois J-M (2005) Rion-Antirion Bridge, Greece - Concept, Design, and Construction. Struct Eng Int 15(1):22-22

De Normalisation CE (1998) Eurocode 8-design of structures for earthquake resistance-part 2: bridges. Eur Stand NF EN 1: 2005

Ganev T, Yamazaki F, Ishizaki H et al (1998) Response analysis of the Higashi-Kobe bridge and surrounding soil in the 1995 Hyogoken-Nanbu earthquake. Earthq Eng Struct Dyn 27(6):557-576

Gimsing NJ, Georgakis CT (2011) Cable supported bridges: concept and design. Wiley, New Jersey, USA.

He WL, Agrawal AK (2008) Analytical model of ground motion pulses for the design and assessment of seismic protective systems. J Struct Eng 134(7):1177-1188

Jangid RS, Kelly JM (2001) Base isolation for near-fault motion. Earthq Eng Struct Dyn 30(5):691-707

Japan Road Association (2002) Specifications for highway bridges. Maruzen, Tokyo

Kite S, Falbe-Hansen K, Vejrum T et al (2005) Stonecutters bridge-design for extreme events. In: Proceedings of the IABSE symposium report. Lisbon: International Association for Bridge and Structural Engineering, 90(2):27-34

Li H, Liu J, Ou J (2009) Investigation of seismic damage of cable-stayed bridges with different connection configuration. J Earthq Tsunami 3(03):227-247

Makris N (1997) Rigidity-plasticity-viscosity: can electrorheological dampers protect base-isolated structures from near-source ground motions? Earthq Eng Struct Dyn 26(5):571-592

Mavroeidis GP, Papageorgiou AS (2003) A mathematical representation of near-fault ground motions. Bull Seismol Soc Am 93(3):1099-1131 
Mazzoni S, McKenna F, Scott MH et al (2006) OpenSees command language manual. Pacific Earthquake Engineering Research (PEER) Center, University of California, Berkeley

MCPRC (2008) Guidelines for seismic design of highway bridges. Ministry of Communications of the People's Republic of China, Beijing (In Chinese)

Mozos CM, Aparicio AC (2011) Numerical and experimental study on the interaction cable structure during the failure of a stay in a cable stayed bridge. Eng Struct 33(8):2330-2341

Nazmy AS, Abdel-Ghaffar AM (1990) Non-linear earthquake response analysis of long-span cable-stayed bridges: theory. Earthq Eng Struct Dyn 19(1):45-62

Ren WX, Obata M (1999) Elastic-plastic seismic behavior of long span cable-stayed bridges. J Bridg Eng 4(3):194-203

Scott BD, Park R, Priestley MJN (1982) Stress-strain behaviour of concrete confined by overlapping hoops at low and high strain rates. J Am Concr Inst 79:13-27

Shrestha B (2015) Seismic response of long span cable-stayed bridge to near-fault vertical ground motions. KSCE J Civ Eng 19(1):180-187

Siringoringo DM, Fujino Y, Namikawa K (2013) Seismic response analyses of the Yokohama Bay cable-stayed bridge in the 2011 great East Japan earthquake. J Bridg Eng 19(8):A4014006

Tan P, Agrawal AK, Pan Y (2005) Near-field effects on seismically excited highway bridge equipped with nonlinear viscous dampers. Bridge Struct 1(3):307-318

Wang R, Xu Y, Li J (2017) Transverse seismic behavior studies of a medium span cable-stayed bridge model with two concrete towers. J Earthq Eng 21(1):151-168

Wesolowsky MJ, Wilson JC (2003) Seismic isolation of cable-stayed bridges for near-field ground motions. Earthq Eng Struct Dyn 32(13):2107-2126

Wu Q, Takahashi K, Nakamura S (2003) The effect of cable loosening on seismic response of a prestressed concrete cablestayed bridge. J Sound Vib 268(1):71-84

Yi J, Li J (2017) Longitudinal seismic behavior of a single-tower cable-stayed bridge subjected to near-field earthquakes. Shock Vib 2017(8):1-16

Yi J, Li J (2019) Experimental and numerical study on seismic response of inclined tower legs of cable-stayed bridges during earthquakes. Eng Struct 183:180-194

Zong ZH, Zhou R, Huang XY et al (2014) Seismic response study on a multi-span cable-stayed bridge scale model under multi-support excitations. Part I: shaking table tests. J Zheijang Univ Sci 15(5):351-363

\section{Publisher's Note}

Springer Nature remains neutral with regard to jurisdictional claims in published maps and institutional affiliations.

\section{Submit your manuscript to a SpringerOpen ${ }^{\circ}$ journal and benefit from:}

- Convenient online submission

Rigorous peer review

- Open access: articles freely available online

- High visibility within the field

- Retaining the copyright to your article

Submit your next manuscript at $\boldsymbol{\nabla}$ springeropen.com 